\title{
Effectiveness of a Brief Group Intervention Program for Young Adults with Gaming-Related Problems
}

\author{
Niko Männikkö ${ }^{1,2}$ (D) Terhi Mustonen ${ }^{3} \cdot$ Niina Tanner $^{3} \cdot$ Hannu Vähänikkilä ${ }^{4}$. \\ Maria Kääriäinen ${ }^{2,5}$
}

Accepted: 24 May 2021 / Published online: 14 June 2021

(C) The Author(s) 2021

\begin{abstract}
Excessive digital gaming can have unfavorable effects on gamers' well-being and everyday functioning. The aims of this study were to investigate the effects of a novel group intervention "Limitless Gaming Bootcamp" on (i) gaming disorder (GD) tendencies, (ii) the amount of time spent on leisure activities, and (iii) subjective well-being among Finnish young adults, and to determine the persistence of the intervention's influence over time. A one-group pre- and post-test design with no control group was used. Thirty-seven participants were enrolled in the study. The inclusion criteria were being between the ages of 18 and 29; self-reported excessive gaming; a willingness to get support in monitoring one's gaming behaviour; and a fluency in Finnish. Participants completed a 10-session group intervention designed to enhance conscious gaming behavior and well-being. Baseline, post-test, and six month follow-up measurements were conducted to gather data. Variables measured included background variables, gaming disorder tendencies (Problematic Online Gaming Questionnaire, POGQ), self-reported time spent on various leisure activities, and subjective well-being (Short Form of the Clinical Outcomes in Routine Evaluation Outcome Measure, CORE-SF/A). The time spent on gaming decreased from pre- to post-intervention measurement and further to the six month follow-up, and participants exhibited less severe GD symptoms during the post-intervention phase and six months after the intervention. Gradual improvements in subjective well-being were also observed. The group intervention was found to be particularly effective at reducing the severity of GD symptoms.
\end{abstract}

Keywords Internet gaming disorder · Gaming disorder treatment · Therapy · Video games

Digital gaming has become a globally popular recreational activity for people of all ages, but sustained excessive gaming may lead to problematic or addictive gaming behavior in a minority of vulnerable gamers (Király et al., 2015). In 1993, the term Internet gaming disorder

Niko Männikkö

mannikkon@gmail.com

Extended author information available on the last page of the article 
was first highlighted in the research appendix of the Diagnostic and Statistical Manual of Mental Disorders (DSM-5) as a condition requiring further research. Following this initial proposal, the World Health Organization (WHO) recognized the most maladaptive gaming pattern as a gaming disorder (GD) in the $11^{\text {th }}$ revision of the International Classification of Diseases (ICD-11) (World Health Organisation, 2018). According to the ICD-11 (WHO, 2018), GD is classified as an addictive disorder characterized by persistent online or offline gaming behavior involving a loss of control over gaming that interferes with and takes priority over other daily life obligations and functions despite the occurrence of unfavorable consequences for at least 12 months (Saunders et al., 2017).

While gaming is mostly harmless, and may even be beneficial in some cases (Granic et al., 2014), GD is associated with several psychosocial problems (González-Bueso et al., 2018; Sugaya et al., 2019), such as loneliness (Krossbakken et al., 2018; Sampogna et al., 2018), low self-esteem (Mihara and Higuchi, 2017; Paulus et al., 2018), and family conflicts (Mihara and Higuchi, 2017; Paulus et al., 2018). It is also associated with comorbid diseases including anxiety and depression (Mentzoni et al., 2011; Müller et al., 2015; Wang, Cho, \& Kim, 2018), somatization (Kim et al., 2016; Starcevic et al., 2011), and obsessive-compulsive disorder (Jiménez-Murcia et al., 2014; Kim et al., 2016; King et al., 2013). GD has also been linked to certain personality tendencies including increased impulsivity (Kim et al., 2016; Walther, Morgenstern, \& Hanewinkel, 2012), aggression and hostility (Kim et al., 2016; Mehroof and Griffiths, 2010), and attention-deficit/hyperactivity (Andreassen et al., 2016; Vadlin et al., 2016). Most studies on the relationship between psychosocial factors and GD are correlational, which limits the scope for all possible comparisons and therefore further prohibiting their ability to confirm causal connections between specific variables (González-Bueso et al., 2018; Männikkö et al., 2017).

There have been some comprehensive and empirically rigorous efforts to assess the prevalence of GD in community samples. A recent systematic review found that the reported population-level prevalence of GD ranged from 0.7 to $27.5 \%$ (Mihara and Higuchi, 2017). For instance, a large-scale study by Rehbein et al. (2015) assessed the prevalence of GD in a sample of 11,003 adolescents aged 13-18 years. In this population, 1.2\% of adolescents were found to satisfy the criteria for GD and 5.1\% were at risk for the condition. In Finland, 1 to $2 \%$ of junior high students (Männikkö et al., 2018) and vocational school students (Männikkö et al., 2019) have been estimated to display GD symptoms; these values are comparable to estimates for other countries. Current evidence also indicates that adolescents in particular are more vulnerable to GD than adults (Mentzoni et al., 2011; Vollmer et al., 2014). Furthermore, males are more likely to show symptoms of GD than females (Gentile et al., 2012; Milani et al., 2018; Yu and Cho, 2016). However, it is worth noting that previous reviews of research in this area have highlighted inconsistencies and weaknesses in the criteria used to assess GD symptoms (King et al., 2013; Király et al., 2015); early instruments simply adapted the DSMIV diagnostic criteria for substance dependence and/or pathological gambling (American Psychiatric Association, 1994).

Current research has increasingly targeted relief from GD and its psychosocial symptoms through different interventions (King et al., 2017; Stevens et al., 2019; Torres-Rodríguez et al., 2018; Zajac et al., 2019). Previous research has shown that in treatment for GD it is important to focus on changes that address dysfunctional thoughts and harmful behavior (King et al., 2017). Consequently, cognitive-behavioral therapy (CBT) has been supported as a treatment approach for gaming-related problems in the past decade (King et al., 2017; Stevens et al., 2019; Zajac et al., 2019). CBT can help individuals identify the underlying causes of GD, and 
find treatment options that fit with their practical difficulties. An apparent benefit of CBT is also that it may address comorbid conditions related to GD (Winkler et al., 2013). Some clinical trials on the treatment of GD have demonstrated benefits (when compared with control groups), but other studies have not found clear therapeutic effects (Stevens et al., 2019).

A recent systematic review (Kim and Noh, 2019) scrutinized the effectiveness of psychological interventions for treating individuals with GD and Internet addiction. Those methods included family-based interventions, CBT, and psychological and/or counseling programs. The review's findings showed that psychological interventions can reduce the severity of addiction. However, the therapeutic outcomes vary widely, which makes the selection and recommendation of any particular procedures or protocols difficult. Additionally, Kim and Noh (2019) reported that interventions are also commonly applied in varying procedures, including individual/group therapy and with or without family-based or Internet-based support.

Many studies on GD interventions have had some notable shortcomings or have yielded inconclusive results (Costa and Kuss, 2019; S. Kim and Noh, 2019; D. L. King et al., 2017; Zajac et al., 2019), indicating that research on various procedures (e.g., family therapy, residential treatment, transcranial stimulation) for GD have also been inconclusive (Zajac et al., 2019). Furthermore, most of the studies on the treatment of GD have been conducted in Asia, particularly in South Korea, and the implications of cultural context on effectiveness are not fully known (King et al., 2017; Stevens et al., 2019). A previous review of research on GD (King et al., 2017) outlines factors lacking in many reported studies, which include (i) a comprehensive follow-up assessment over at least 3 to 6 months, (ii) methods for identifying changes in diagnosis by combining results from baseline and follow-up assessments (i.e., determination of recovery and relapse), (iii) broad evaluations of intervention outcomes including changes in quality of life and cognition, and (iv) evaluations of lasting (i.e., posttreatment) psychosocial and environmental adaptations following interventions. In addition, there is a need for new ways of detecting and treating early phase GD symptoms before the condition gets worse.

As mentioned above, most previous studies have focused on psychological therapies utilizing CBT. However, the exact content of CBT models for GD is not fully described in the literature (King et al., 2017; King and Delfabbro, 2014). Consequently, little is known about how CBT might lead to therapeutic effects. Furthermore, the interventions have focused almost exclusively on individuals exhibiting severe symptoms of GD (King et al., 2017). There also appear to be unresolved questions regarding what programs are optimal for the prevention of GD among the two groups of regular or hazardous gamers (Stevens et al., 2021). Taken together, the available evidence suggests that both new means to prevent and treat problematic gaming and further research to establish evidence-based GD prevention and treatment are needed.

Because of the novel status of GD and the fact that its treatments are still in the exploratory phase, there is also a need for interventions that target problematic gaming behaviors prior to the full range of GD symptoms emerging. Many young adults who play video games intensively do not consider themselves to be problem gamers (Király et al., 2017), which may cause them to avoid seeking clinical treatment even when it is needed. Nevertheless, these gamers may recognize some problematic aspects of their gaming behavior and be at least somewhat concerned about the effect of gaming on their lives. This makes it important to create and provide forms of early interventions and support that avoid stigmatization and motivate gamers to make changes before their condition gets worse. 
The aim of the present study is to investigate the feasibility and effects of a new easyaccess group intervention, Limitless Gaming Bootcamp, on gamers' GD tendencies, and subjective well-being among Finnish young adults. The intervention offers specialized psycho-educational features and peer support for young adults who play video games excessively. The intervention is not a consummate psychological treatment protocol; rather, it is an effort to develop an easy-access intervention procedure that is convenient in nonclinical circumstances.

The intervention follows the ideas of the biopsychosocial theory of addiction, where gaming-related problems are considered to be a consequence of various individual (e.g., social and cognitive factors, well-being), situational (e.g., gaming environment), and structural (e.g., gaming genres) factors that all interact with each other (Griffiths, 2005). Knowledge is also lacking on how education or treatment procedures including such elements as situational and structural factors influence gaming behavior and subjective experiences. Therefore, the intervention suggested here employs various applied techniques that help gamers self-reflect on the role of influential factors (subjective norms, well-being, cognitive and self-regulatory factors, gaming motives and environment, game genres, social competence) in relation to their gaming behavior.

It has been hypothesised that Limitless Gaming Bootcamp be associated with improvements in the following goal outcomes: (i) conscious gaming behavior (measured based on GD symptoms and time spent gaming - Hypothesis 1); (ii) subjective well-being (immediately and six months after intervention - Hypothesis 2); and (iii) the balance between gaming and other free-time activities in post-intervention and follow-up phases (increased proportion of nongaming-related behavior outcomes - Hypothesis 3).

\section{Methods}

\section{Sample and Procedure}

The intervention was targeted at intense adult gamers wishing to reduce the effects of gaming on their daily lives. Participants were recruited from five cities in different geographic regions of Finland (Kuopio, Tampere, Helsinki, Jyväskylä, and Oulu), where intervention groups were organized at youth centers and other accessible facilities. Participation was free-of-charge for all participants.

During the enrolment phase, invitation letters including information sheets and an outline of the program were emailed to various healthcare and social service organizations. Invitation letters were also distributed directly to the target group using posters and flyers, and via the websites and Facebook adverts of the host organization (Sosped Foundation). Targeted contacts were also made directly via partner organizations, which took care of group arrangements and counselling in the five cities.

The inclusion criteria for study participants were (1) aged between 18 and 29 years; (2) selfreported excessive gaming and willingness to get external support to monitor one's gaming behavior; (3) voluntary participation in the group intervention; (4) granting oral and written consent to participate; and (5) fluency in Finnish. Exclusion criteria were (1) having a severe disorder or mental symptoms that would affect regular participation in the program and (2) not providing oral and written consent to participate. 
Comprehensive information on the participants was gathered at the beginning of the intervention period (i.e., preintervention phase [T0] prior to the first group session) using a paper/pencil survey. Study participants were reassessed using the same survey at the end of group intervention (i.e., post-intervention phase [T1], following the last group session), and again six months after completing the intervention (i.e., follow-up phase [T2]). The follow-up survey was conducted as a traditional mail response data collection. Data from all three time points are used in the current paper. No control group was assigned.

The Ethics Committee of North Ostrobothnia's hospital district approved the study, and informed consent was obtained from the study participants. All participants were assured that they could withdraw from the intervention or the study at any time they wished.

\section{Description of the Intervention}

A total of 44 young adults participated in the five intervention groups, of which 37 individuals (mean age of 23.8 years, SD $=2.84$ ) participated in the study. The primary aim of the intervention was to prevent the development of more severe problematic gaming behaviors and promote gamers' overall well-being. The intervention was commissioned by a nonprofit non-governmental organization (Sosped Foundation) in collaboration with various partner organizations that contributed to the execution of intervention groups. Each intervention group was guided by an experienced social or health care professional (partner organization) and a trained "peer coach" (Sosped Foundation), who worked as a pair. Peer coaches were young adult volunteers with a personal history of problematic gaming. All of them had completed $54 \mathrm{~h}$ (2 ECTS) of training on problematic gaming and group instruction skills. The groups followed the weekly predesigned intervention program (Table 1), though there were some slight variations in the individual assignments and discussion topics chosen by the instructors of the groups.

Table 1 Weekly themes of the meetings in relation to biopsychosocial theory

\begin{tabular}{|c|c|c|}
\hline Theme & $\begin{array}{l}\text { Determinants of } \\
\text { biopsychosocial theory }\end{array}$ & Target outcome \\
\hline 1. Introduction and goals & $\begin{array}{l}\text { Individual, situational, and } \\
\text { structural }\end{array}$ & $\begin{array}{l}\text { Conscious gaming behavior; healthier behavior } \\
\text { choices; well-being }\end{array}$ \\
\hline 2. Well-being and video games & Individual & $\begin{array}{l}\text { Conscious gaming behavior; healthier behavior } \\
\text { choices; well-being }\end{array}$ \\
\hline 3. My gaming history & $\begin{array}{l}\text { Individual, situational, and } \\
\text { structural }\end{array}$ & Conscious gaming behavior \\
\hline $\begin{array}{l}\text { 4. Gaming motivation and } \\
\text { game design }\end{array}$ & $\begin{array}{l}\text { Individual, situational, and } \\
\text { structural }\end{array}$ & Conscious gaming behavior \\
\hline 5. Everyday time management & Individual & $\begin{array}{l}\text { Conscious gaming behavior; healthier behavior } \\
\text { choices; well-being }\end{array}$ \\
\hline $\begin{array}{l}\text { 6. Social skills and } \\
\text { connectedness }\end{array}$ & Individual, situational & Healthier behavior choices (social); well-being \\
\hline $\begin{array}{l}\text { 7. Physical health and gaming } \\
\text { ergonomics }\end{array}$ & Individual & Healthier behavior choices (physical); well-being \\
\hline 8. Healthy diet & Individual & Healthier behavior choices; well-being \\
\hline $\begin{array}{l}\text { 9. Invited } \\
\text { visitor/excursion/hobby trial }\end{array}$ & Individual, situational & Healthier behavior choices; well-being \\
\hline 10. Conclusions and next steps & $\begin{array}{l}\text { Individual, situational, and } \\
\text { structural }\end{array}$ & $\begin{array}{l}\text { Conscious gaming behavior; healthier behavior } \\
\text { choices; well-being }\end{array}$ \\
\hline
\end{tabular}


The group intervention took around three months to complete and consisted of ten weekly sessions of $3 \mathrm{~h}$ each. Table 1 describes the main themes addressed in each of the ten group sessions.

The present work has utilised an early-phase educational intervention as a suitable framework aiming at affecting individuals' influential factors on the GD. At the beginning of the intervention, participants were asked to set individual goals for the program. One of the key elements of the intervention was to change the perspective of participants regarding their high engagement in gaming. These changes in attitudes (subjective norms) were reinforced by supporting participants' self-perception on their gaming behavior, gaming history, and environments/situations that trigger gaming, as well as on how gaming motives might be associated with gamers' everyday choices, decision making, and further health behavior (wellbeing). Another key element was to increase participants' awareness of the particular structural characteristic utilized in digital games (game design and gamification), and the relevance of "addictive features" in relation to engagement in gaming. Evaluation of the structural and environmental factors of gaming was also of gaming was supposed to help individuals also to recognize situational factors that might influence their gaming behavior. Assignments relating to time management and behavioral change were used to demonstrate the role of gaming in participants' everyday lives in relation to other activities. Instructor-guided thematic discussion and group activities were used to build and strengthen participants' social awareness, social networking, problem solving, and social skills. In particular, social gaming (e.g., video games, board games, card games, serious games) was introduced to the group program as a common ground for social interaction and peer support.

Each group session thus included instructor-guided group discussions, skill training, and/or behavior change assignments and common activities. The meeting routine consisted of (i) a warmup ("how are you today?", $30 \mathrm{~min}$ ); (ii) theme of the week (60 min); (iii) snack break (15 min); (iv) social gaming (60 min); and (v) wrap-up and reflection ("what did you learn today?", $15 \mathrm{~min}$ ).

\section{Measurements}

Data were collected at the baseline (T0), post-test (T1), and six month follow-up (T2) time points using questionnaires. The primary outcomes were the impact on the symptoms of problematic gaming, the impact on the time spent on gaming and various other leisure activities, and the measure of subjective wellbeing.

Gaming disorder symptoms were measured using the Problematic Online Gaming Questionnaire (POGQ), which examines gaming-related problems on six dimensions: a preoccupation with games, withdrawal symptoms, overuse in terms of amount of gaming, immersion, social isolation, and interpersonal conflict (Demetrovics et al., 2012). The scale includes 18 items rated on a 5-point Likert scale (ranging from 1 "never" to 5 "always"). The participants' scores for each item on the scale were added to generate combined scores, with higher scores corresponding to more severe problematic gaming symptoms. The POGQ scale was previously found to have satisfactory psychometric properties in a Finnish-speaking sample (Männikkö et al., 2018). The instrument also exhibited good internal consistency $(\alpha=0.90)$ based on the baseline data for this study.

Participants were asked to report the average amount of time (in minutes) that they spent on various leisure activities such as exercise, music, reading, social interaction, television viewing, Internet, and digital gaming on a typical weekday and weekend day. Based on this activity 
data, an average daily use variable was generated for each activity: average daily use = $[($ weekday time $\times 5)+($ weekend day time $\times 2)] / 7$.

The subjective well-being was assessed using the short form of the Clinical Outcomes in Routine Evaluation Outcome Measure (CORE-SF/A). The original 34-item self-report measure (CORE-OM) reflects users' subjective well-being by asking about common symptoms in four domains: subjective well-being (assessed using four items, including "I have felt tense, anxious or nervous" and "I have felt like crying"), problems (six items, including "I have felt unhappy" and "I have felt despairing or hopeless"), functioning (six items, including "I have felt able to cope when things go wrong" and "I have achieved the things I wanted to"), and risk (two items, including "I thought of hurting myself" and "I have hurt myself physically or taken risks with my health") (Barkham et al., 1998, 2001). Two parallel 18-item short forms (CORE-SF: forms A and B) based on the main domains have also been developed (Barkham et al., 2001; Cahill et al., 2006). In the current study, an 18-item form CORE-SFA was used. Participants are asked to respond to each item based on their experiences over the last week using a 5-point Likert scale ranging from 0 "not at all" to 4 "most or all of the time" (except five items that are reverse-scored). Total scores ranged from 0 to 90 , with higher scores indicating more severe perceived distress symptoms. The full 34-item version of CORE-OM showed adequate psychometric properties in a Finnish-speaking sample (Honkalampi et al., 2017). The internal consistency of the CORE-SFA was acceptable $(\alpha=0.69)$ based on the baseline data for this study.

Sociodemographic data were gathered by asking participants to report their gender, age, marital status (single, in a relationship or married/cohabiting), level of education (under 9 years of primary education/primary education; upper secondary education: matriculation; upper secondary education: vocational qualification; basic higher education [bachelor/master]; other education), and occupation (employed: permanent full-time job/temporary full-time job/parttime job/self-employed/ entrepreneur; student; out of work: unemployed/retired/sick leave/sick daily allowance/other reason out of job/studies).

\section{Statistical Analysis}

There were no missing data for any of the sociodemographic variables other than education status $(2 / 37 ; 5.4 \%)$. Across the data collection phases, the proportion of missing data varied between 0 and $18.5 \%$; the variable with the highest level of missing data was that for social activities during the weekend in the T1 phase. A linear mixed model (LMM) was generated using the statistical software SPSS version 22 (IBM Corp., Armonk, NY, USA). The mixed model enables the analysis of unbalanced datasets without using imputation, and thus all available data were analyzed using maximum likelihood methods (Kortekangas et al., 2019). The primary outcomes (gaming time, gaming-related problems, time spent on other leisure activities, and well-being) evaluated using the LMM were changes from the baseline to the post-intervention and follow-up phases in the amount of time spent on different leisure activities and the severity of problematic gaming symptoms (i.e., the repeatedly measured continuous study variables). Effect sizes with 95\% confidence intervals (CI) for the post-intervention (T1) and post-treatment (T2) phases were estimated using the LMM. Changes were considered statistically significant based on two-tailed $p$ values of less than 0.05 . 


\section{Attrition Analysis}

At the starting point (T0), 37 participants responded. In the second post-intervention phase (T1), 27 individuals responded (retention rate 72.9\%); in the final follow-up phase (T2), 6 responded (retention rate 16.2\%). Compared to participants who completed the intervention measurements (i.e., those who responded at both $\mathrm{T} 0$ and $\mathrm{T} 1$ ), participants who dropped out before T1 spent somewhat more time on gaming (a mean of 294 vs. $393 \mathrm{~min}, p=0.184$ ), had more severe GD symptoms (with POGQ scores of 42.4 vs. 52.1, $p=0.039$ ), and had a slightly higher level of distress (with CORE scores of 21.8 vs. 23.7, $p=0.497$ ). In addition, participants who responded at T2 spent less time on gaming (with a mean time of 223 vs. $342 \mathrm{~min}, p=0.128$ ), had less severe GD symptoms (with mean POGQ scores of 36.3 vs. 46.7, $p=0.071$ ), and had a slightly higher level of distress symptoms (with CORE scores of $22.8 \mathrm{vs}$. $22.2, p=0.861)$.

\section{Results}

The baseline characteristics of the participants are presented in Table 2. Most of the participants $(83.8 \%)$ were male. The mean age of the participants was 23.8 years $(\mathrm{SD}=2.84)$. A majority $(81.1 \%)$ were currently not in a relationship. In terms of educational level, $34.3 \%$ had completed primary school and $34.3 \%$ had completed vocational school. Most of the participants $(73 \%)$ were not working (unemployed, retired, or on long-term leave).

The baseline, post-intervention, and 6-month follow-up parameters (means and standard deviations) are presented in Table 3. The mean POGQ scores ranged from 45.0 (T0) to 38.4 (T1) and 30.7 (T2) with a significant negative trend between the baseline (T0) and posttreatment phases $(\mathrm{T} 1)\left(F_{(2,70)}=4.31 p=0.017\right)$. In general, there was a negative trend in gaming time $\left(F_{(2,59)}=1.53, p=0.420\right)$ across the measurement time points. Furthermore, there were increasing rates of Internet use $\left(F_{(2,61)}=0.36, p=0.695\right.$, ns) from the baseline (mean time, $188.9 \mathrm{~min}$ ) to $\mathrm{T} 1$ (mean time, $223.0 \mathrm{~min}$ ); this increase was reversed between $\mathrm{T} 1$ and $\mathrm{T} 2$

Table 2 Baseline characteristics

\begin{tabular}{lc}
\hline Variable & Number $(\%)$ \\
\hline Gender & $31(83.8)$ \\
Male & $6(16.2)$ \\
Female & \\
Marital status & $30(81.1)$ \\
Single & $5(13.5)$ \\
In a relationship & $2(5.4)$ \\
Married or cohabiting & $12(34.3)$ \\
Education level & $12(34.3)$ \\
Primary school & $8(22.9)$ \\
Matriculation exam & $2(5.7)$ \\
Secondary/vocational school & $1(2.9)$ \\
Higher (Bachelor, master or PhD) & $1(2.7)$ \\
Other & $27(73.0)$ \\
Occupation status & $9(24.3)$ \\
Active/employed (employee, executive, etc.) & \\
Inactive/out of work (without work, retired, long-term leave) & \\
Student & \\
\hline
\end{tabular}




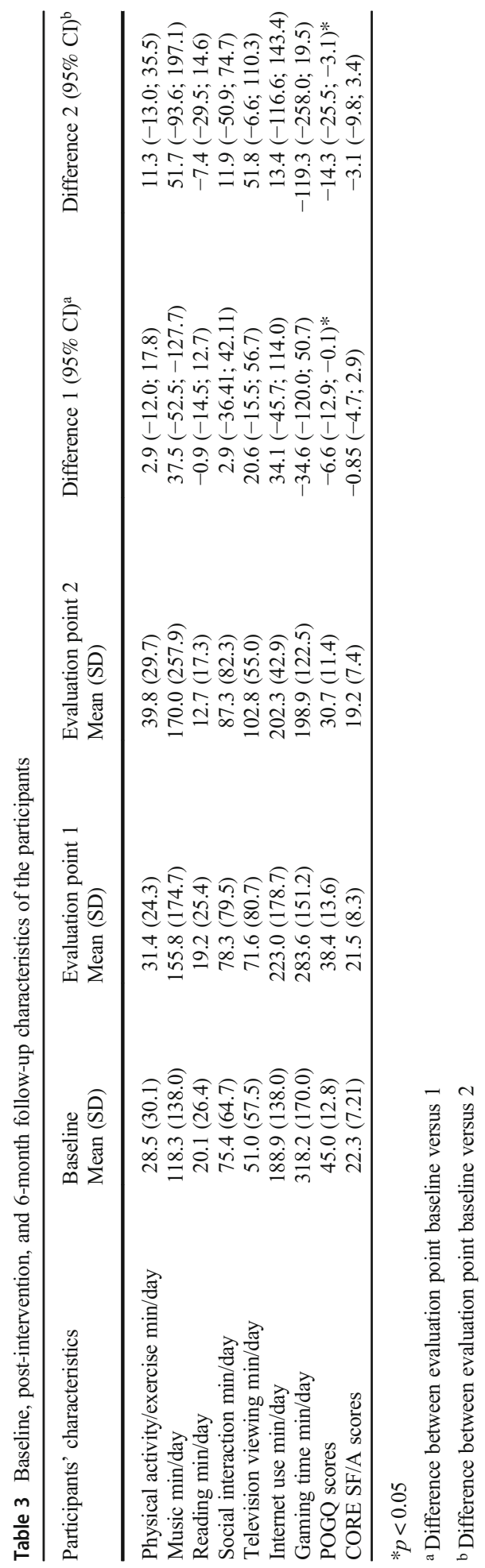


(mean time, $202.3 \mathrm{~min}$ ). The indicator of social connection with friends and relatives also exhibited a positive trend over time $\left(F_{(2,59)}=0.073, p=0.930, \mathrm{~ns}\right)$. The mean distress scores used as an indicator of subjective well-being ranged from 22.3 (T0) to 19.2 (T2) with a decreasing but non-significant trend over the three time points $\left(F_{(2,69)}=0.490, p=0.614\right)$, suggesting progressively better well-being over time.

\section{Discussion}

This study delineated the influences of a novel group intervention (Limitless Gaming Bootcamp) for developing conscious gaming behavior with respect to GD tendencies in a nonclinical sample of Finnish young adults. The effects of the intervention were assessed by measuring gaming time, gaming-related problems, time spent on other common leisure activities, and subjective well-being. Measurements were conducted at a baseline timepoint, immediately after the intervention, and after a 6-month follow-up period.

As anticipated in Hypothesis 1, the severity of GD symptoms reduced significantly during the intervention and the follow-up period relative to the baseline. Gradual improvements (albeit non-significant) in the time spent on gaming and subjective well-being were also observed over time (which partly supported Hypothesis 2). However, participation in the group did not produce any significant changes in the gamers' daily non-gaming-related freetime activities (contrary to Hypothesis 3). This current study supports the view that participation in the Limitless Gaming Bootcamp group intervention helped alleviate or suppress problematic gaming habits, although resulting changes in the participants' other daily routines were minor.

The intervention attracted significantly more male than female participants. As noted previously, males tend to show more interest and to spend more time on gaming and gaming-related activities (Kuss, 2013; Vollmer et al., 2014). Moreover, males are more likely to be prone to problematic gaming (Choo et al., 2015; Lee and Kim, 2017).

The results presented here support the view that even nontherapeutic group intervention (including group discussions, skill training and behavior change assignments) can be useful in alleviating or suppressing symptoms associated with GD among young adults. Participants in this study exhibited significantly reduced levels of GD symptoms during both the postintervention and follow-up (around 6 months) phases, which is comparable to other studies on psychoeducational treatments for GD (King et al., 2017; Torres-Rodríguez et al., 2018; Zajac et al., 2019). These previous studies utilized CBT as the therapeutic approach for supporting gamers' self-regulatory techniques (to modify dysfunctional thoughts and patterns of behavior, alongside goal-setting and self-monitoring). It is worth noting that the present group intervention was not directly based on CBT and was not an actual therapy, even though it included some quite similar elements (e.g. it focused on individuals' conscious gaming behavior, subjective attitudes, self-regulatory and situational factors, and gaming motives). A recent meta-analysis found that CBT in particular is very efficient at reducing the severity of gaming-related problems in post-intervention and follow-up phases (Stevens et al., 2019). The authors of this analysis also noted however that few studies in this area have included followup assessments. In those studies that included a follow-up phase, these periods varied greatly (e.g., between 8 weeks and 12 months).

Gaming played an important role in the lives of the study participants throughout the intervention, and social game playing was also used within the intervention program to 
enhance group coherence, fellowship, and trust. Even though gaming still seemed to play a role in participants' lives at the end of the intervention period, the program succeeded to alleviate the participants' gaming-related problems, most likely by providing participants with tools to control their behavior and pursue it in a more balanced and healthy way. According to the biopsychosocial theory, a range of individual, environmental, and structural factors influence gaming behavior (Griffiths, 2005). This intervention program adapted existing methods that targeted these influential factors for gaming behavior, in order to help the participants understand the nature and meaning of their gaming-related problems. A benefit of this approach was that it supported participants to enhance their self-management of gaming behavior. For instance, participants were found to increase their social and physical activities slightly during the post-intervention and follow-up phases. An additional advantage of the present approach is that it not only addressed factors at the individual level, but also took into account the social and environmental effects; and thus, it was likely more effective in facilitating behavioral change. Previous evidence supports the view that the use of theory in planning and executing behavior change interventions increases the effectiveness of interventions (Michie and Johnston, 2012).

It is worth noting that the study participants who played most excessively and reported most severe symptoms of problematic gaming were more likely to drop out of the program (low treatment engagement). This could be explained by a lower level of readiness to change or intrinsic motivation within these participants. To the author's knowledge, there is a lack of studies that have thoroughly scrutinized predictors of, or reasons for, treatment attrition (adherence) in the field. The degree to which gaming-related problems are recognized probably plays a role in motivation and readiness to engage in long-term treatment and behavioral change. Furthermore, the individuals need to believe that the behavior is compatible with their values and/or life goals, and they need to feel capable of achieving the change. Research has yielded the insight that poorer self-control (self-management of emotions, thoughts, and behaviors) is associated with more severe gaming-related problems and inflexible gaming motivations (Mills and Allen, 2020). In light of this, and the challenge of adhering to treatment, action (identifying concrete steps for implementation), coping (identifying ways to overcome possible barriers), and planning (e.g., previously adopted for gamblers; Rodda et al., 2020) may help lower gamers' intention-behavior barriers and support their selfregulation. Beyond gamers' self-management support, it could be argued that a follow-up reminder (e.g., a short call), including discussion of progress, would give participants individualized attention, and thus would be effective in producing adherence and the desired changes.

The step-by-step intervention examined here aims to modify participants' maladaptive beliefs about gaming behavior (by increasing conscious gaming involvement) and possible other unpleasant feelings that are particularly present when not playing games. This cognitive bias is related to impaired control of gaming behavior and plays a prominent role in motivational drive toward reward-seeking (Dong and Potenza, 2014). Similarly, it is notable that individuals with GD symptoms may pursue gaming to cope with negative feelings and possibly to experience feelings such as dominance and social acceptance (D. King et al., 2010; Yee, 2006). The participants' increased Internet use during the intervention period could thus be partly explained as a compensatory strategy (Kardefelt-Winther, 2014) used to meet such needs (reward, self-esteem, and social acceptance) and provide the feelings previously obtained by gaming.

In addition to their reduced GD symptoms, participants who completed the program reported slight reductions in distress symptoms in the post-intervention and follow-up phases. 
This finding provides support for the view that interventions should target potential comorbid conditions in addition to actual GD. Improvement of subjects' well-being in turn may reflect their improved sense of competence in controlling their own behavior and problems, as recent reviews have consistently reported a connection between higher degrees of GD symptoms and distress and/or comorbid disorders (González-Bueso et al., 2018; Männikkö et al., 2017; Mihara and Higuchi, 2017). To better understand control over gaming involvement, future studies should include more comprehensive assessment of gaming behavior including the length of gaming periods, frequency of gaming within the days, the number and length of breaks during gaming sessions, and other variables that may limit gaming exposure, and/or number of days without gaming (Stevens et al., 2019). In addition, future studies should examine the duration of the problem, along with the mental health factors.

Comprehensive improvements in health-related behavior must be assessed over extended periods of time. It could be argued that the intervention (three months) and follow-up (six months) periods were too short to induce and verify deep and lasting long-term changes in individual behavior given the number of psychoeducational topics addressed by the program. However, it is worth noting that clinical severity of GD was not among the inclusion criteria for our intervention sample. Previous longitudinal studies conducted over periods of 1-2 years have found that the temporal stability of GD can vary greatly between individuals, from $<1$ to 84\% (Gentile et al., 2011; Krossbakken et al., 2018; Rothmund et al., 2018; Strittmatter et al., 2016; Van Rooij et al., 2011). However, it appears that the natural progress of GD is likely to be more stable among youths than adults (Mihara and Higuchi, 2017).

This study has some limitations that should be noted. First, it is based on a relatively small unrandomized sample with no control group. In addition, a minority of the participants completed the assessments at follow-up (six months after the intervention), which reflects a relatively high retention rate in comparison to the meager existing data on treatment for GD with adult samples (Li et al., 2017). Post-intervention (follow-up) outcome data were gathered using a traditional mail response form that might explain some decrease in participation. Thus, the conclusions presented here should be considered preliminary and care should be taken in generalizing the findings. However, it is worth noting that recent reviews have highlighted the fact that a limited number of studies have included the follow-up assessments (King et al., 2017; Stevens et al., 2019). Future studies should use larger samples to verify the effectiveness of the intervention used here. The data used in this work are based on self-reports and are therefore susceptible to self-report bias (memory recall and social desirability). Furthermore, the study included outcome measures assessing gaming time, gaming-related problems, nongaming-related free-time activities, and well-being. It was not possible to determine the exact benefits arising from all elements of the intervention (e.g. situational and environmental factors or social and physical health). Thus, a more comprehensive assessment setting along with objective measures (e.g., gaming over day phases, gaming environment) should be employed in future studies. In sum, further studies involving bigger sample sizes including control groups are needed to minimize biases relating to the single-group approach. It would also be desirable to examine samples with more balanced demographic characteristics to obtain stronger statistical evidence.

Despite these limitations, this work indicates that even easy-access light touch groups (and non-actual therapy-like) interventions that emphasize education on conscious gaming behavior and social well-being can have positive impacts for gamers seeking help to control their gaming behavior. Additionally, based on six months of follow-up, the effects seem to be permanent among the participants committed to the program. This kind of brief group 
intervention is also cost-effective and provides social support from other participants who are in the same situation.

Larger controlled studies with robust long-term follow-up evaluations are needed to verify the efficacy of the studied intervention in gamers. Future studies should also take advantage of multimethod behavioral measurements and further investigate potential mediators of outcomes.

Funding Open access funding provided by University of Oulu including Oulu University Hospital. Limitless Gaming program is supported by the Funding Centre for Social Welfare and Health Organisations in Finland (grant C 2822, 2017). Financial support was received for this study from Juho Vainio Foundation.

\section{Declarations}

Ethics Approval The study procedure was conducted in accordance with the Declaration of Helsinki.

Conflict of Interest The authors declare no conflict of interest.

Informed Consent All participants provided informed consent, and participation was voluntary.

Open Access This article is licensed under a Creative Commons Attribution 4.0 International License, which permits use, sharing, adaptation, distribution and reproduction in any medium or format, as long as you give appropriate credit to the original author(s) and the source, provide a link to the Creative Commons licence, and indicate if changes were made. The images or other third party material in this article are included in the article's Creative Commons licence, unless indicated otherwise in a credit line to the material. If material is not included in the article's Creative Commons licence and your intended use is not permitted by statutory regulation or exceeds the permitted use, you will need to obtain permission directly from the copyright holder. To view a copy of this licence, visit http://creativecommons.org/licenses/by/4.0/.

\section{References}

American Psychiatric Association. (1994). Diagnostic and statistical manual of mental disorders. In Diagnostic and statistical manual of mental disorders (4th ed.).

Andreassen, C. S., Billieux, J., Griffiths, M. D., Kuss, D. J., Demetrovics, Z., Mazzoni, E., \& Pallesen, S. (2016). The relationship between addictive use of social media and video games and symptoms of psychiatric disorders: A large-scale cross-sectional study. Psychology of Addictive Behaviors, 30(2), 252-262. https:// doi.org/10.1037/adb0000160.

Barkham, M., Evans, C., Margison, F., Mcgrath, G., Mellor-Clark, J., Milne, D., \& Connell, J. (1998). The rationale for developing and implementing core outcome batteries for routine use in service settings and psychotherapy outcome research. Journal of Mental Health, 7(1), 35-47. https://doi.org/10.1080/ 09638239818328.

Barkham, M., Leach, C., Lucock, M., Evans, C., Margison, F., Mellor-Clark, J., Benson, L., Connell, J., Audin, K., \& McGrath, G. (2001). Service profiling and outcomes benchmarking using the CORE-OM: Toward practice-based evidence in the psychological therapies. Journal of Consulting and Clinical Psychology, 69(2), 184-196. https://doi.org/10.1037/0022-006X.69.2.184.

Cahill, J., Barkham, M., Stiles, W. B., Twigg, E., Hardy, G. E., Rees, A., \& Evans, C. (2006). Convergent validity of the CORE measures with measures of depression for clients in cognitive therapy for depression. Journal of Counseling Psychology, 53(2), 253-259. https://doi.org/10.1037/0022-0167.53.2.253.

Choo, H., Sim, T., Liau, A. K. F., Gentile, D. A., \& Khoo, A. (2015). Parental influences on pathological symptoms of video-gaming among children and adolescents: A prospective study. Journal of Child and Family Studies, 24(5), 1429-1441. https://doi.org/10.1007/s10826-014-9949-9. 
Costa, S., \& Kuss, D. J. (2019). Current diagnostic procedures and interventions for gaming disorders: A systematic review. Frontiers in Psychology, 10(MAR). https://doi.org/10.3389/fpsyg.2019.00578.

Demetrovics, Z., Urbán, R., Nagygyörgy, K., Farkas, J., Griffiths, M. D., Pápay, O., Kökönyei, G., Felvinczi, K., \& Oláh, A. (2012). The development of the problematic online gaming questionnaire (POGQ). PLoS One, 7(5), e36417. https://doi.org/10.1371/journal.pone.0036417.

Dong, G., \& Potenza, M. N. (2014). A cognitive-behavioral model of Internet gaming disorder: Theoretical underpinnings and clinical implications. Journal of Psychiatric Research, 58, 7-11. https://doi.org/10.1016/ j.jpsychires.2014.07.005.

Gentile, D. A., Choo, H., Liau, A., Sim, T., Li, D., Fung, D., \& Khoo, A. (2011). Pathological video game use among youths: a two-year longitudinal study. Pediatrics, 127(2), e319-e329. https://doi.org/10.1542/peds. 2010-1353.

Gentile, D. A., Swing, E. L., Lim, C. G., \& Khoo, A. (2012). Video game playing, attention problems, and impulsiveness: Evidence of bidirectional causality. Psychology of Popular Media Culture, 1(1), 62-70. https://doi.org/10.1037/a0026969.

González-Bueso, V., Santamaría, J. J., Fernández, D., Merino, L., Montero, E., \& Ribas, J. (2018). Association between Internet gaming disorder or pathological video-game use and comorbid psychopathology: A comprehensive review. International Journal of Environmental Research and Public Health, 15(4). https://doi.org/10.3390/ijerph15040668.

Granic, I., Lobel, A., \& Engels, R. C. M. E. (2014). The benefits of playing video games. American Psychologist, 69(1), 66-78. https://doi.org/10.1037/a0034857.

Griffiths, M. (2005). A "components" model of addiction within a biopsychosocial framework. Journal of Substance Use, 10, 191-197. https://doi.org/10.1080/14659890500114359.

Honkalampi, K., Laitila, A., Juntunen, H., Lehmus, K., Piiparinen, A., Törmänen, I., Inkinen, M., \& Evans, C. (2017). The Finnish Clinical Outcome in Routine Evaluation Outcome Measure: Psychometric exploration in clinical and non-clinical samples. Nordic Journal of Psychiatry, 71(8), 589-597. https://doi.org/10.1080/ 08039488.2017.1365378.

Jiménez-Murcia, S., Fernández-Aranda, F., Granero, R., Chóliz, M., La Verde, M., Aguglia, E., Signorelli, M. S., Sá, G. M., Aymamí, N., Gómez-Peña, M., Del Pino-Gutiérrez, A., Moragas, L., Fagundo, A. B., Sauchelli, S., Fernández-Formoso, J. A., \& Menchón, J. M. (2014). Video game addiction in gambling disorder: Clinical, psychopathological, and personality correlates. BioMed Research International, 2014, 2014, 1-11. https://doi.org/10.1155/2014/315062.

Kardefelt-Winther, D. (2014). A conceptual and methodological critique of Internet addiction research: Towards a model of compensatory internet use. Computers in Human Behavior, 31(1), 351-354. https://doi.org/10. 1016/j.chb.2013.10.059.

Kim, N. R., Hwang, S. S. H., Choi, J. S., Kim, D. J., Demetrovics, Z., Király, O., Nagygyörgy, K., Griffiths, M. D., Hyun, S. Y., Youn, H. C., \& Choi, S. W. (2016). Characteristics and psychiatric symptoms of Internet gaming disorder among adults using self-reported DSM-5 criteria. Psychiatry Investigation, 13(1), 58-66. https://doi.org/10.4306/pi.2016.13.1.58.

Kim, S., \& Noh, D. (2019). The current status of psychological intervention research for Internet addiction and Internet gaming disorder. Issues in Mental Health Nursing, 40(4), 335-341. https://doi.org/10.1080/ 01612840.2018 .1534910 .

King, D. L., \& Delfabbro, P. H. (2014). Internet gaming disorder treatment: A review of definitions of diagnosis and treatment outcome. Journal of Clinical Psychology, 70, 942-955. https://doi.org/10.1002/jclp.22097.

King, D., Delfabbro, P., \& Griffiths, M. (2010). Video game structural characteristics: A new psychological taxonomy. International Journal of Mental Health and Addiction, 8(1), 90-106. https://doi.org/10.1007/ s11469-009-9206-4.

King, D. L., Delfabbro, P. H., Wu, A. M. S., Doh, Y. Y., Kuss, D. J., Pallesen, S., Mentzoni, R., Carragher, N., \& Sakuma, H. (2017). Treatment of Internet gaming disorder: An international systematic review and CONSORT evaluation. Clinical Psychology Review, 54, 123-133. https://doi.org/10.1016/j.cpr.2017.04. 002 .

King, D. L., Haagsma, M. C., Delfabbro, P. H., Gradisar, M., \& Griffiths, M. D. (2013). Toward a consensus definition of pathological video-gaming: A systematic review of psychometric assessment tools. Clinical Psychology Review, 33(3), 331-342. https://doi.org/10.1016/j.cpr.2013.01.002.

Király, O., Griffiths, M. D., \& Demetrovics, Z. (2015). Internet gaming disorder and the DSM-5: Conceptualization, debates, and controversies. Current Addiction Reports, 2(3), 254-262. https://doi.org/ 10.1007/s40429-015-0066-7.

Király, O., Nagygyörgy, K., Koronczai, B., Griffiths, M. D., \& Demetrovics, Z. (2015). Assessment of problematic Internet use and online video gaming. In Mental Health in the Digital Age (pp. 46-68). https://doi.org/10.1093/med/9780199380183.003.0003. 
Király, O., Tóth, D., Urbán, R., Demetrovics, Z., \& Maraz, A. (2017). Intense video gaming is not essentially problematic. Psychology of Addictive Behaviors, 31(7), 807-817. https://doi.org/10.1037/adb0000316.

Kortekangas, T., Haapasalo, H., Flinkkilä, T., Ohtonen, P., Nortunen, S., Laine, H. J., Järvinen, T. L., \& Pakarinen, H. (2019). Three week versus six week immobilisation for stable Weber B type ankle fractures: Randomised, multicentre, non-inferiority clinical trial. The BMJ., k5432. https://doi.org/10.1136/bmj.k5432.

Krossbakken, E., Pallesen, S., Mentzoni, R. A., King, D. L., Molde, H., Finserås, T. R., \& Torsheim, T. (2018). A cross-lagged study of developmental trajectories of video game engagement, addiction, and mental health. Frontiers in Psychology, 9. https://doi.org/10.3389/fpsyg.2018.02239.

Kuss, D. J. (2013). Internet gaming addiction: Current perspectives. Psychology Research and Behavior Management, 6, 125-137. https://doi.org/10.2147/PRBM.S39476.

Lee, C., \& Kim, O. (2017). Predictors of online game addiction among Korean adolescents. Addiction Research and Theory, 25(1), 58-66. https://doi.org/10.1080/16066359.2016.1198474.

Li, W., Garland, E. L., Mcgovern, P., O’brien, J. E., Tronnier, C., \& Howard, M. O. (2017). Mindfulnessoriented recovery enhancement for internet gaming disorder in U.S. adults: A stage I randomized controlled trial. Psychology of Addictive Behaviors, 31, 393-402. https://doi.org/10.1037/adb0000269.

Männikkö, N., Demetrovics, Z., Ruotsalainen, H., Myllymäki, L., Miettunen, J., \& Kääriäinen, M. (2018). Psychometric properties of the Problematic Gaming Questionnaire used to assess Finnish adolescents. International Journal of Mental Health and Addiction, 18, 103-111. https://doi.org/10.1007/s11469-0189943-3.

Männikkö, N., Ruotsalainen, H., Miettunen, J., Pontes, H. M., \& Kääriäinen, M. (2017). Problematic gaming behaviour and health-related outcomes: A systematic review and meta-analysis. Journal of Health Psychology, 25, 135910531774041. https://doi.org/10.1177/1359105317740414.

Männikkö, N., Ruotsalainen, H., Tolvanen, A., \& Kääriäinen, M. (2019). Psychometric properties of the Internet Gaming Disorder Test (IGDT-10) and problematic gaming behavior among Finnish vocational school students. Scandinavian Journal of Psychology, 60(3), 252-260. https://doi.org/10.1111/sjop.12533.

Mehroof, M., \& Griffiths, M. D. (2010). Online gaming addiction: The role of sensation seeking, self-control, neuroticism, aggression, state anxiety, and trait anxiety. Cyberpsychology, Behavior and Social Networking, 13(3), 313-316. https://doi.org/10.1089/cyber.2009.0229.

Mentzoni, R. A., Brunborg, G. S., Molde, H., Myrseth, H., Skouverøe, K. J. M., Hetland, J., \& Pallesen, S. (2011). Problematic video game use: Estimated prevalence and associations with mental and physical health. Cyberpsychology, Behavior and Social Networking, 14(10), 591-596. https://doi.org/10.1089/cyber.2010. 0260 .

Michie, S., \& Johnston, M. (2012). Theories and techniques of behaviour change: Developing a cumulative science of behaviour change. In Health Psychology Review., 6, 1-6. https://doi.org/10.1080/17437199.2012. 654964.

Mihara, S., \& Higuchi, S. (2017). Cross-sectional and longitudinal epidemiological studies of Internet gaming disorder: A systematic review of the literature. Psychiatry and Clinical Neurosciences, 71(7), 425-444. https://doi.org/10.1111/pcn.12532.

Milani, L., La Torre, G., Fiore, M., Grumi, S., Gentile, D. A., Ferrante, M., Miccoli, S., \& Di Blasio, P. (2018). Internet gaming addiction in adolescence: Risk factors and maladjustment correlates. International Journal of Mental Health and Addiction, 16(4), 888-904. https://doi.org/10.1007/s11469-017-9750-2.

Mills, D. J., \& Allen, J. J. (2020). Self-determination theory, Internet gaming disorder, and the mediating role of self-control. Computers in Human Behavior, 105, 106209. https://doi.org/10.1016/j.chb.2019.106209.

Müller, K. W., Janikian, M., Dreier, M., Wölfling, K., Beutel, M. E., Tzavara, C. (2015). Regular gaming behavior and internet gaming disorder in European adolescents: Results from a cross-national representative survey of prevalence, predictors, and psychopathological correlates. European Child and Adolescent Psychiatry, 24(5), 565-574. https://doi.org/10.1007/s00787-014-0611-2

Paulus, F. W., Ohmann, S., von Gontard, A., \& Popow, C. (2018). Internet gaming disorder in children and adolescents: A systematic review. Developmental Medicine and Child Neurology, 60, 645-659. https://oi. org/10.1111/dmcn.13754.

Rehbein, F., Kliem, S., Baier, D., Mößle, T., \& Petry, N. M. (2015). Prevalence of internet gaming disorder in German adolescents: Diagnostic contribution of the nine DSM-5 criteria in a state-wide representative sample. Addiction, 110(5), 842-851. https://doi.org/10.1111/add.12849.

Rodda, S. N., Bagot, K. L., Manning, V., \& Lubman, D. I. (2020). An exploratory RCT to support gamblers' intentions to stick to monetary limits: a brief intervention using action and coping planning. Journal of Gambling Studies. https://doi.org/10.1007/s10899-019-09873-w.

Rothmund, T., Klimmt, C., \& Gollwitzer, M. (2018). Low temporal stability of excessive video game use in German adolescents. Journal of Media Psychology, 30(2), 53-65. https://doi.org/10.1027/1864-1105/ a000177. 
Sampogna, G., Del Vecchio, V., Luciano, M., Giallonardo, V., Palummo, C., Pocai, B., Steardo, L., Bhugra, D., \& Fiorillo, A. (2018). Is Internet gaming disorder really a new form of mental disorder? A critical overview. Journal of Psychopathology.

Saunders, J. B., Hao, W., Long, J., King, D. L., Mann, K., Fauth-Bühler, M., Rumpf, H. J., Bowden-Jones, H., Rahimi-Movaghar, A., Chung, T., Chan, E., Bahar, N., Achab, S., Lee, H. K., Potenza, M., Petry, N., Spritzer, D., Ambekar, A., Derevensky, J., Griffiths, M. D., Pontes, H. M., Kuss, D., Higuchi, S., Mihara, S., Assangangkornchai, S., Sharma, M., Kashef, A. E., Ip, P., Farrell, M., Scafato, E., Carragher, N., \& Poznyak, V. (2017). Gaming disorder: Its delineation as an important condition for diagnosis, management, and prevention. Journal of Behavioral Addictions, 6(3), 271-279. https://doi.org/10.1556/2006.6.2017.039.

Sofia, V., Cecilia, Å., Charlotta, H., \& Kent.W., N. (2016). Associations between problematic gaming and psychiatric symptoms among adolescents in two samples. Addictive Behaviors, 61, 8-15. https://doi.org/10. 1016/j.addbeh.2016.05.001

Starcevic, V., Berle, D., Porter, G., \& Fenech, P. (2011). Problem video game use and dimensions of psychopathology. International Journal of Mental Health and Addiction, 9(3), 248-256. https://doi.org/ 10.1007/s11469-010-9282-5.

Stevens, M. W. R., Delfabbro, P. H., \& King, D. L. (2021). Prevention approaches to problem gaming: A largescale qualitative investigation. Computers in Human Behavior, 115, 106611. https://doi.org/10.1016/j.chb. 2020.106611 .

Stevens, M. W. R., King, D. L., Dorstyn, D., \& Delfabbro, P. H. (2019). Cognitive-behavioral therapy for Internet gaming disorder: A systematic review and meta-analysis. Clinical Psychology \& Psychotherapy, 26(2), 191-203. https://doi.org/10.1002/cpp.2341.

Strittmatter, E., Parzer, P., Brunner, R., Fischer, G., Durkee, T., Carli, V., Hoven, C. W., Wasserman, C., Sarchiapone, M., Wasserman, D., Resch, F., \& Kaess, M. (2016). A 2-year longitudinal study of prospective predictors of pathological Internet use in adolescents. European Child and Adolescent Psychiatry, 25(7), 725-734. https://doi.org/10.1007/s00787-015-0779-0.

Sugaya, N., Shirasaka, T., Takahashi, K., \& Kanda, H. (2019). Bio-psychosocial factors of children and adolescents with internet gaming disorder: A systematic review. BioPsychoSocial Medicine, 13(1), 3. https://doi.org/10.1186/s13030-019-0144-5.

Torres-Rodríguez, A., Griffiths, M.D. \& Carbonell, X. (2018). The Treatment of Internet Gaming Disorder: a Brief Overview of the PIPATIC Program. International Journal of Mental Health and Addiction, 16, 10001015. https://doi.org/10.1007/s11469-017-9825-0

Vadlin, S., Åslund, C., Hellström, C., \& Nilssons, K. W. (2016). Associations between problematic gaming and psychiatric symptoms among adolescents in two samples. Addictive Behaviors, 61, 8-15. https://doi.org/10. 1016/j.addbeh.2016.05.001.

Van Rooij, A. J., Schoenmakers, T. M., Vermulst, A. A., Van Den Eijnden, R. J. J. M., \& Van De Mheen, D. (2011). Online video game addiction: Identification of addicted adolescent gamers. Addiction, 106(1), 205212. https://doi.org/10.1111/j.1360-0443.2010.03104.x.

Vollmer, C., Randler, C., Horzum, M. B., \& Ayas, T. (2014). Computer game addiction in adolescents and its relationship to chronotype and personality. SAGE Open, 4(1), 215824401351805. https://doi.org/10.1177/ 2158244013518054.

Walther, B., Morgenstern, M., \& Hanewinkel, R. (2012). Co-occurrence of addictive behaviours: Personality factors related to substance use, gambling and computer gaming. European Addiction Research, 18(4), 167174. https://doi.org/10.1159/000335662

Wang, H.R., Cho, H., \& Kim, D.J. (2018). Prevalence and correlates of comorbid depression in a nonclinical online sample with DSM-5 internet gaming disorder. Journal of Affective Disorder, 15(226), 1-5. https://doi. org/10.1016/j.jad.2017.08.005.

Winkler, A., Dörsing, B., Rief, W., Shen, Y., \& Glombiewski, J. A. (2013). Treatment of internet addiction: a meta-analysis. In Clinical Psychology Review., 33, 317-329. https://doi.org/10.1016/j.cpr.2012.12.005.

World Health Organisation. (2018). WHO $\mid$ International classification of diseases, 11th revision (ICD-11) (Vol. 30, pp. 8336-8341). WHO. https://doi.org/10.1021/la501744u.

Yee, N. (2006). Motivations for play in online games. CyberPsychology and Behavior, 9(6), 772-775. https:// doi.org/10.1089/cpb.2006.9.772.

Yu, H., \& Cho, J. (2016). Prevalence of internet gaming disorder among Korean adolescents and associations with non-psychotic psychological symptoms, and physical aggression. American Journal of Health Behavior, 40(6), 705-716. https://doi.org/10.5993/AJHB.40.6.3.

Zajac, K., Ginley, M. K., \& Chang, R. (2019). Treatments of internet gaming disorder: a systematic review of the evidence. Expert Review of Neurotherapeutics, 20, 85-93. https://doi.org/10.1080/14737175.2020.1671824. 
Publisher's Note Springer Nature remains neutral with regard to jurisdictional claims in published maps and institutional affiliations.

\section{Affiliations}

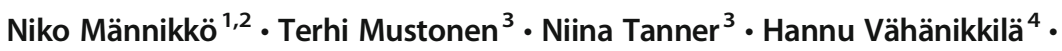
Maria Kääriäinen ${ }^{2,5}$

1 School of Health and Social Care, Oulu University of Applied Sciences, Oulu, Finland

2 Research Unit of Nursing Science and Health Management, University of Oulu, P.O. Box 5000, FI90014 Oulu, Finland

3 Sosped Foundation, Helsinki, Finland

4 Infrastructure of Population Studies, University of Oulu, Oulu, Finland

5 Oulu University Hospital, Oulu, Finland 